\title{
A qualitative study of motivators and barriers to weight reduction practices among overweight and obese suburban Malay adults
}

\author{
Wirdah Mohamed, Syaznie Enre, Poh Bee Koon \& Ruzita Abd Talib* \\ Nutritional Sciences Programme \& Centre for Community Health Studies (ReaCH), \\ Faculty of Health Sciences, Universiti Kebangsaan Malaysia, Kuala Lumpur, \\ Malaysia
}

\begin{abstract}
Introduction: Designing an effective and comprehensive weight reduction intervention requires an understanding of the motivating factors and barriers to losing weight. This study explored the motivating factors and barriers to weight reduction through the experiences, emotions and ideas shared among suburban overweight and obese Malay adults. Methods: In this qualitative study, 23 overweight or obese Malay adults aged 30-59 years old were divided into three focus group discussion (FGD). The Socio-Ecological Model (SEM), consisting of four levels (intrapersonal, interpersonal, community, and policy) was utilised in this study. Results: The motivating factors were: (1) Intrapersonal level: self-awareness, health concern, self-confidence, and desire to have good physical appearance, (2) Interpersonal level: social support from family and friends, (3) Community level: availability and accessibility of physical activity facilities and health information, and (4) Policy level: healthy lifestyle programme. The barriers were: (1) Intrapersonal level: lack of knowledge about diet, physical limitations, lack of self-control, and emotion/mood, (2) Interpersonal level: spouse and children, career or housework commitment, (3) Community level: lack of neighbourhood safety, and availability and accessibility of outside foods, and (4) Policy level: availability and accessibility of outside foods. Conclusion: Eight factors were identified as motivating factors and barriers for weight reduction practices. Support from family and friends should be considered when developing an effective and comprehensive weight loss programme as it was both a motivating factor as well as a barrier.
\end{abstract}

Keywords: Motivator, barrier, weight reduction, obesity, qualitative study

\section{INTRODUCTION}

The World Health Organization estimates that obesity rates around the world have nearly tripled between 1975 and 2016. It was estimated that in 2016, 1.9 billion adults over the age of 18 years were overweight. Of these adults, more than 650 million were obese. These figures indicated that in 2016,
$39 \%$ of the world's adult population was overweight and $13 \%$ obese (WHO, 2017). According to the National Health and Morbidity Survey (NHMS) 2019, the prevalence of adult obesity in Malaysia was $19.7 \%$ and overweight $30.4 \%$. The prevalence of obesity in adults aged $\geq 18$ years increased from $15.1 \%$ in 2011 to $17.7 \%$ in 2015 , and to $19.7 \%$ in 2019

\footnotetext{
*Corresponding author: Prof. Dr. Ruzita Abd Talib

Nutritional Sciences Programme \& Centre For Community Health, Faculty of Health Sciences, Universiti Kebangsaan Malaysia, Jalan Raja Muda Abd Aziz, 50300 Kuala Lumpur, Malaysia Tel: (6)(03) -9289 7622; Fax: (6)(03)-2694 7621; E-mail: rzt@ukm.edu.my doi: https://doi.org/10.31246/mjn-2019-0139
} 
(IPH, 2020). As reported in NHMS 2015, the states with the highest prevalence of obesity in Malaysia were the Federal Territory of Putrajaya (43.0\%), followed by Malacca (36.0\%) (IPH, 2015).

Unhealthy diet and lack of physical activities are associated with weight gain and increased risks of many health problems. Obesity contributes to health problems such as cardiovascular diseases, type 2 diabetes, osteoarthritis, and cancer, as well as negatively impacting quality of life (Lau et al., 2013). However, reducing weight through healthy eating and being physically active is challenging and involves many barriers (Fitzgerald \& Spaccarotella, 2009).

Therefore, understanding the motivating factors and barriers to losing weight is important in developing effective weight loss programmes and for longterm positive results (Hammarstrom et al., 2014). Barriers reduce the tendency of individuals to get involved in health intervention programmes. Lack of selfcontrol, thus cheating during diet intervention, was identified as a major barrier to weight loss among participants, while family, friends and project-related support were motivators for them to lose weight (Hammarstrom et al., 2014).

In order to improve and optimise future behavioural lifestyle intervention programmes, a greater understanding of the barriers and motivating factors of obese people from the individual level to socio-environment level is required. The whole ecological system must be given attention in understanding human development, as it consists of subsystems that assist, support and guide human development. They include relationships between individuals and their immediate environment such as school and family, up to the macro system, which is the cultural pattern of institutions (Fitzgerald \& Spaccarotella, 2009).
Ecological model approach for health promotion focuses on both individual and social environmental factors. Any changes in the social environment will influence changes in an individual, and the support of individuals in the population is important for implementing environmental changes. It has been used as a basis for identifying determinants of behaviour such as smoking, physical activity, and nutrition. According to the Socio-Ecological Model (SEM) of health behaviour, four main factors that influence health behaviour include intrapersonal, interpersonal, community, and policy factors (Fitzgerald \& Spaccarotella, 2009)

However, barriers and motivating factors on behaviouralchanges for healthy eating and physical activity are generally focused on individual or intrapersonal level, although environmental factors are important for a multifaceted approach in behavioural lifestyle changes (Fitzgerald \& Spaccarotella, 2009). In Malaysia, studies on motivators and barriers in weight reduction from a multifaceted approach are still lacking. Most studies and intervention programmes that have been carried out focus on intrapersonal factors which influence obesity such as individual knowledge, attitudes and skills, and the effects of intervention on anthropometric and metabolic variables (Noor Safiza et al., 2016; Roszanadia et al., 2016). In addition, there were only a few qualitative studies on self-perception and barriers that had been conducted among Malaysian obese individuals (Nur Shahida et al., 2016) and body weight perception among adolescents (Kuan et al., 2011). Therefore, the aim of our qualitative study is to gain more insight into the motivating factors and barriers associated with weight loss, based on the four levels of factors that influence health behaviour in the SEM framework. 


\section{MATERIALS AND METHODS}

\section{Study design}

The study design was a qualitative research and data were collected through focus group discussions (FGD) to explore the motivating factors and barriers to losing weight. FGD was used to obtain qualitative data on specific topics from multiple individuals through informal group discussions. This method provides data or feedback that may not be found in any record or documentation via dynamic conversation when a group of people ask questions from each other or debate in a short time period. Another advantage of FGD is the environment, which is socially oriented to help individuals express their experiences and perceptions, and discuss their ideas, opinions and thoughts. The study protocol was reviewed and approved by the Universiti Kebangsaan Malaysia Research Ethics Committee (UKM/ PPI/ 111/8JEP-2016-207).

\section{Study participants}

Purposive sampling method was used to obtain the sample for this study. Sample selection was conducted in Alor Gajah, Malacca as Malacca is the second state with the highest prevalence of obesity in Malaysia (IPH, 2015). Thirty-seven participants were recruited from the Fit, Eat, Active, Training (F.E.A.T.) programme, which was designed as a quasi-experimental study (Wirdah et al., 2020). Screening was conducted to identify participants based on the inclusion criteria of this study. Inclusion criteria were Malay adults aged 3059 years old with a body mass index (BMI) $\geq 25.0 \mathrm{~kg} / \mathrm{m}^{2}$, without physical disabilities or any serious hearing or speech problems, interested to lose weight and at the contemplation phase in reference to the Transtheoretical Model (TTM) (Lenio, 2006). These inclusion criteria had taken into account the national population surveys, which have reported that the prevalence of overweight and obesity among the middle age group was doubled compared to other age groups, and the study subjects who were all Malay adults, as they appeared to have a faster rate of increase in obesity, compared to Indian and Chinese adults (Ghee, 2016).

\section{Development of FGD interview guidelines}

FGD interview guidelines were developed by the research team and reviewed by two qualitative researchers from the Malaysian Ministry of Health. The interview guidelines had a list of openended questions to enable respondents to fully express their personal opinions, perceptions and experiences during the discussions. The questions were divided into four topics: (1) motivators for weight loss, (2) respondents' experiences in their attempts to lose weight, (3) barriers to obtaining a weight loss, and (4) the ideal weight loss programme. The questions on experiences in attempts to lose weight and the ideal weight loss programme provided unprompted answers for motivating factors and barriers in weight loss, which enabled the researcher to obtain maximum input from the participants. The topics were chosen after consideration of relevant factors on motivators and barriers to lose weight through some references (Fitzgerald \& Spaccarotella, 2009; Bethancourt et al., 2014; Christaldi \& Dejoy, 2012) and expert's opinion.

Pre-testing of FGD interview guidelines was done twice and included 30 overweight individuals in suburban Kuala Lumpur and eight overweight individuals in Seremban. The first pretest was done to assess the relevance and understandability of the questions, while the second pre-test was done to test the appropriate environment and to improve the skill of the moderator. 


\section{Data collection}

Data for the study were obtained via FGDs conducted among the participants at Alor Gajah, Malacca. A total of 37 participants were invited to participate in the study through letters and phone calls, and appointments were scheduled for subjects to participate in the FGDs. However, only 23 participants showed up for the FGD sessions. The participants were divided into three groups. The FGDs were conducted in a closed and comfortable room, with each group scheduled separately. The participants provided written consent and brief sociodemographic information before the start of the discussion. The participants granted permission for audio and visual recordings of the sessions to be made. All discussions were conducted for approximately an hour and a half to two hours, facilitated by the same trained moderator.

\section{Data analysis}

Audio files were transcribed verbatim and internal reliability was checked by research team members who read the transcripts and listened to the audio files several times to confirm that the data had been correctly transcribed. Interaction data were obtained from the audio tapes, video records, and notes taken by the observer during the discussion sessions to ensure rigorous data analysis.

The transcripts were coded independently by two researchers (WM and $\mathrm{SE}$ ). The codes were interpreted into two content areas, which were motivating factors and barriers to losing weight (Bethancourt et al., 2014; Christaldi \& Dejoy, 2012). Thematic analysis was carried out to identify condensed main themes through these coded segments. After that, the codes were brought together into preliminary sub-themes, which were then sorted into themes after discussion among the researchers and external peer reviewers, and lastly into final sub-themes and themes. Two researchers then identified and categorised themes based on the SEM, which comprised of four levels: (1) interpersonal, (2) intrapersonal, (3) community, and (4) policy (Fitzgerald \& Spaccarotella, 2009).

Each FGD transcript was imported into the NVivo computer software (version $11,2015)$ as a rich text document. NVivo was used to extract codes and themes from the participants' responses and to obtain reference numbers $(n)$ for all themes referring to the statements issued by the participants.

\section{Theme consensus with the researcher}

Two external peer reviewers read the transcripts to identify and form the themes. After the external peer reviewers have determined the appropriate themes, two researchers (WM and SE) compared and discussed the themes. The validation of themes was achieved through consensus between the two researchers and the two external peer reviewers. The identified codes, subthemes and themes for two content areas of motivating factors and barriers to losing weight are described in Table 1.

\section{RESULTS}

\section{Themes for motivating factors to lose weight}

Table 2 shows the themes for motivating factors to lose weight and the responses from participants during the FGD sessions. All participants were those who were interested in weight reduction and many had previous experiences in weight loss, whereby majority of them had previously tried to lose weight in different ways, but without success. They expressed a general wish to lose weight in order to avoid chronic diseases and had a high self-awareness about their health. They stressed that the health hazards of being overweight were more 
important than the desire to have a nice appearance. Participants also had selfconfidence to lose weight with guidance and support. From the FGDs, we also found the need for social support. Social support was very important as their motivator to lose weight. Other than that, the availability and accessibility of physical activity facilities and health information were also needed as a

Table 1. Codes, sub-themes, themes and number of reference for motivating factors and barriers to losing weight

\begin{tabular}{|c|c|c|c|}
\hline Codes & Sub-themes & Themes & $n$ \\
\hline \multicolumn{4}{|l|}{ Motivating factors to losing weight } \\
\hline - Easy to find attire that fits & - Appearance & - Desire to have & 17 \\
\hline $\begin{array}{l}\text { - Want to have beautiful body and } \\
\text { image }\end{array}$ & - Beautiful body & $\begin{array}{l}\text { good physical } \\
\text { appearance }\end{array}$ & \\
\hline \multicolumn{4}{|l|}{ - Looks attractive like other people } \\
\hline - Increased risk of diseases & $\begin{array}{l}\text { - Concern about } \\
\text { potential diseases }\end{array}$ & - Health concern & 24 \\
\hline \multirow{2}{*}{\multicolumn{4}{|c|}{$\begin{array}{l}\text { - Advice by doctor } \\
\text { - Uncomfortable with self- } \\
\text { condition }\end{array}$}} \\
\hline & & & \\
\hline \multirow{2}{*}{$\begin{array}{l}\text { - Knows their own body weight } \\
\text { status } \\
\text { - } \quad \text { Ageing }\end{array}$} & $\begin{array}{l}\text { - Overweight and } \\
\text { obese }\end{array}$ & - Self-awareness & 29 \\
\hline & $\begin{array}{l}\text { - Age and risk of } \\
\text { diseases }\end{array}$ & & \\
\hline \multirow{5}{*}{ 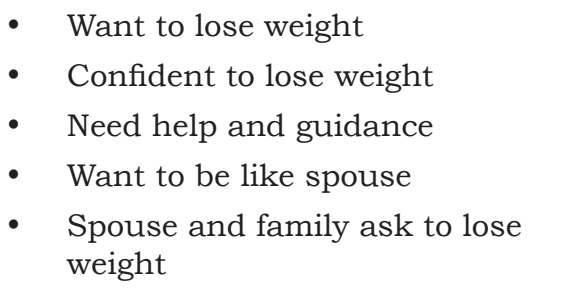 } & - Can reduce weight & - Self confidence & 17 \\
\hline & by guidance on & & \\
\hline & how to weight loss & & \\
\hline & - Family and spouses' & - Family and & 25 \\
\hline & ern & & \\
\hline \multirow{2}{*}{$\begin{array}{l}\text { - Need friend to exercise with } \\
\text { - Facilities for exercise provided in } \\
\text { the community }\end{array}$} & - Friends' influences & & \\
\hline & $\begin{array}{l}\text { - Facilities provided } \\
\text { in community }\end{array}$ & $\begin{array}{l}\text { - Availability and } \\
\text { accessibility }\end{array}$ & 20 \\
\hline $\begin{array}{l}\text { Safe and convenient facilities for } \\
\text { exercise }\end{array}$ & & of physical & \\
\hline $\begin{array}{l}\text { Information on physical activity } \\
\text { and exercise provided in the } \\
\text { community }\end{array}$ & $\begin{array}{l}\text { Information } \\
\text { provided in } \\
\text { community }\end{array}$ & information & \\
\hline \multicolumn{4}{|l|}{$\begin{array}{l}\text { - Information about diet and } \\
\text { exercise for weight loss }\end{array}$} \\
\hline \multirow{2}{*}{$\begin{array}{l}\text { Healthy lifestyle activities } \\
\text { conducted by nearest health } \\
\text { clinic } \\
\text { Join healthy lifestyle activity, } \\
\text { such as } 10,000 \text { steps } \\
\text { programme, and free medical } \\
\text { check-up }\end{array}$} & $\begin{array}{l}\text { Healthy lifestyle } \\
\text { activity conducted } \\
\text { by nearest health }\end{array}$ & $\begin{array}{l}\text { - Healthy lifestyle } \\
\text { programme }\end{array}$ & 7 \\
\hline & clinic & & \\
\hline
\end{tabular}


Table 1. Codes, sub-themes, themes and number of reference for motivating factors and barriers to losing weight [Cont'd]

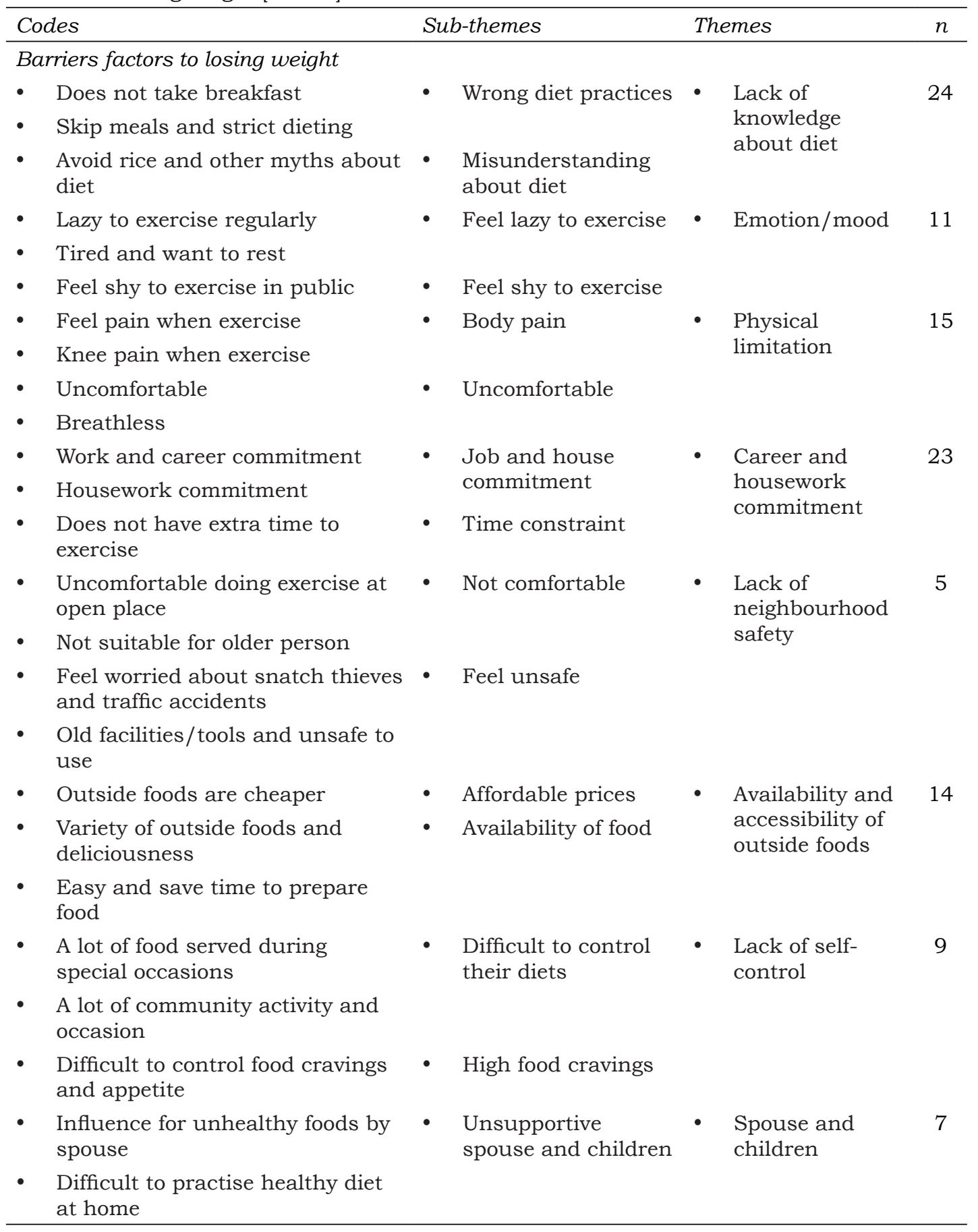

$n=$ reference numbers for all themes 


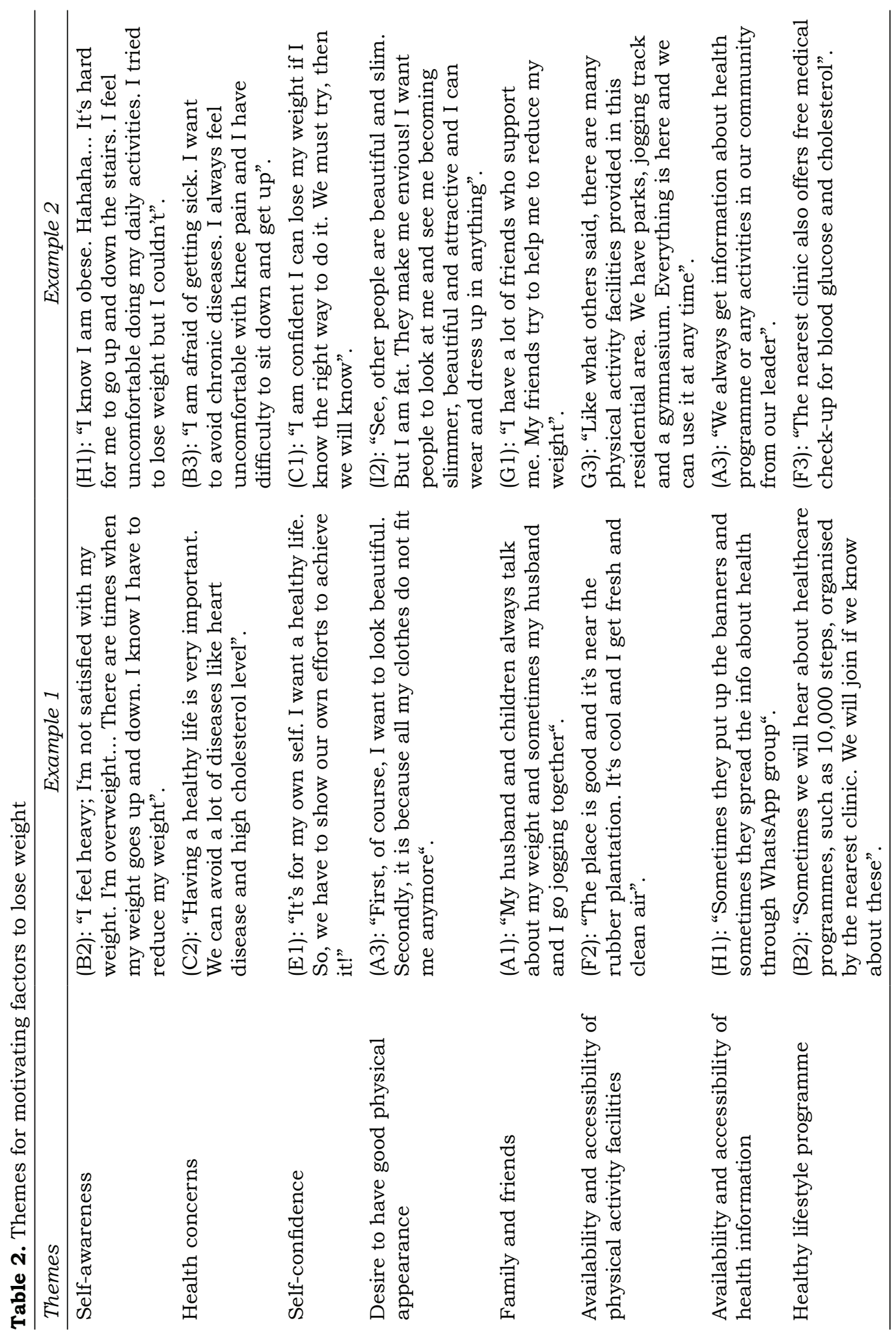


motivator to be more concerned about their weight and to be more active. Healthy lifestyle programmes organised by the nearest government clinics had also influenced them to be more active.

\section{Themes for barriers to losing weight}

Table 3 shows the themes for barriers to losing weight among the participants. The main barriers to weight loss were the lack of knowledge about diet, having physical limitations to be involved in physical activities or to exercise, lack of self-control in adhering to healthy diets, and feeling shy or uncomfortable to exercise alone. Some spouses and children influenced them to eat unhealthy foods, and their career or house-work commitment has resulted in a lack of time, which was an obstacle for them to lose weight. From the discussion, some of the participants mentioned safety issues and expressed their concerns about the rise in kidnapping cases and accidents, which made them worried to exercise outdoors. They also complained that they cannot control their desire for foods and were always looking out for unhealthy foods.

\section{Socio-ecological model for motivating factors and barriers of weight loss among the participants}

The identified themes for motivating factors and barriers to weight loss presented at the intrapersonal, interpersonal, community, and policy levels of Socio-Ecological Model (Fitzgerald \& Spaccarotella, 2009) are described in the conceptual framework titled "Motivating factors and barriers of weight loss found in the study" (Figure 1). Eight motivators and barriers had been identified and categorised into four levels of SEM. Intrapersonal level factors are factors mostly within the control of an individual. The motivating factors for intrapersonal level were self-awareness, health concern, self-confidence, and desire to have good physical appearance. Intrapersonal barriers to losing weight were lack of knowledge about diet, lack of self-control, physical limitations, and emotion or mood.

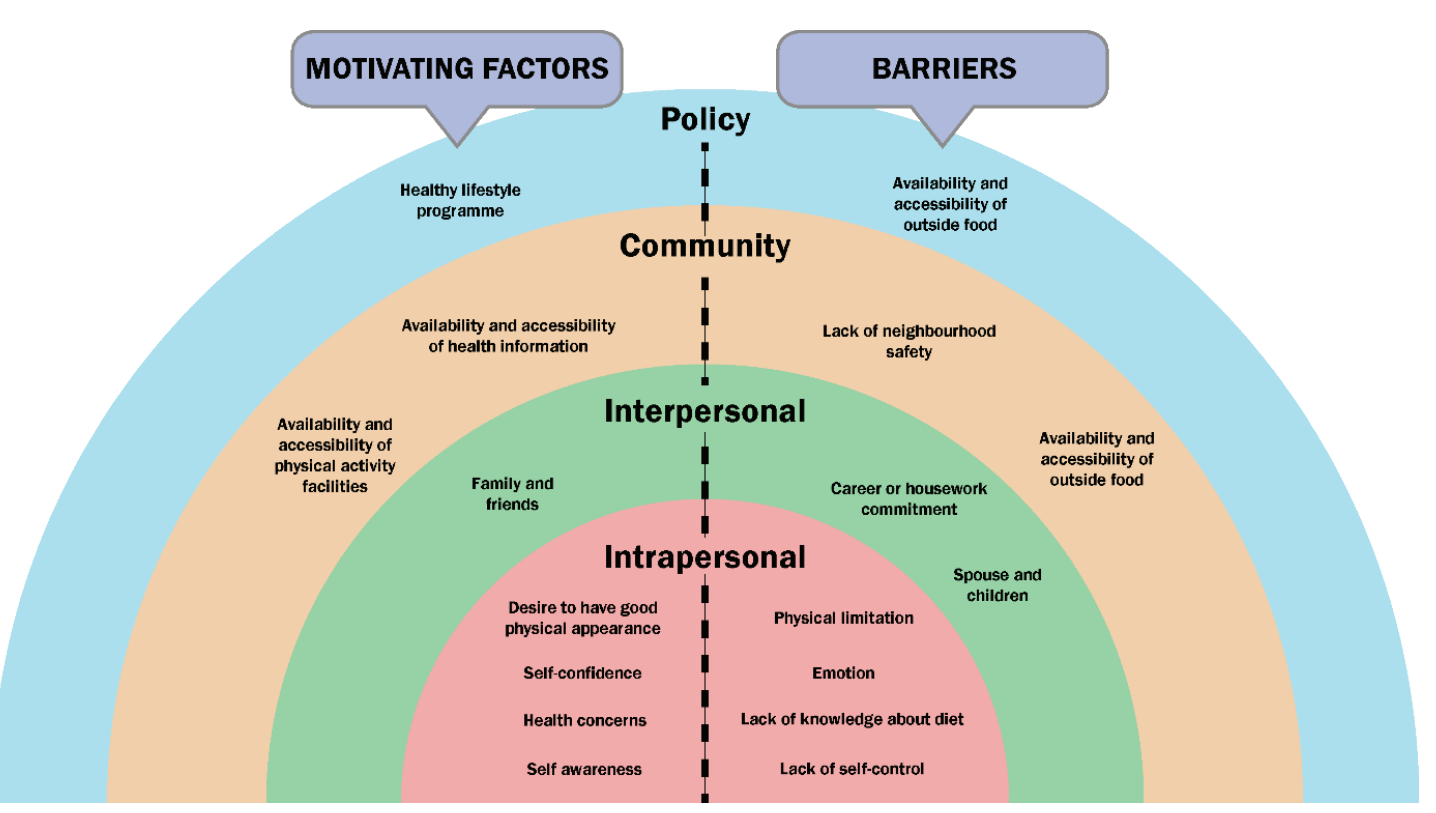

Figure1. Motivating factors and barriers of weight loss found in the study 


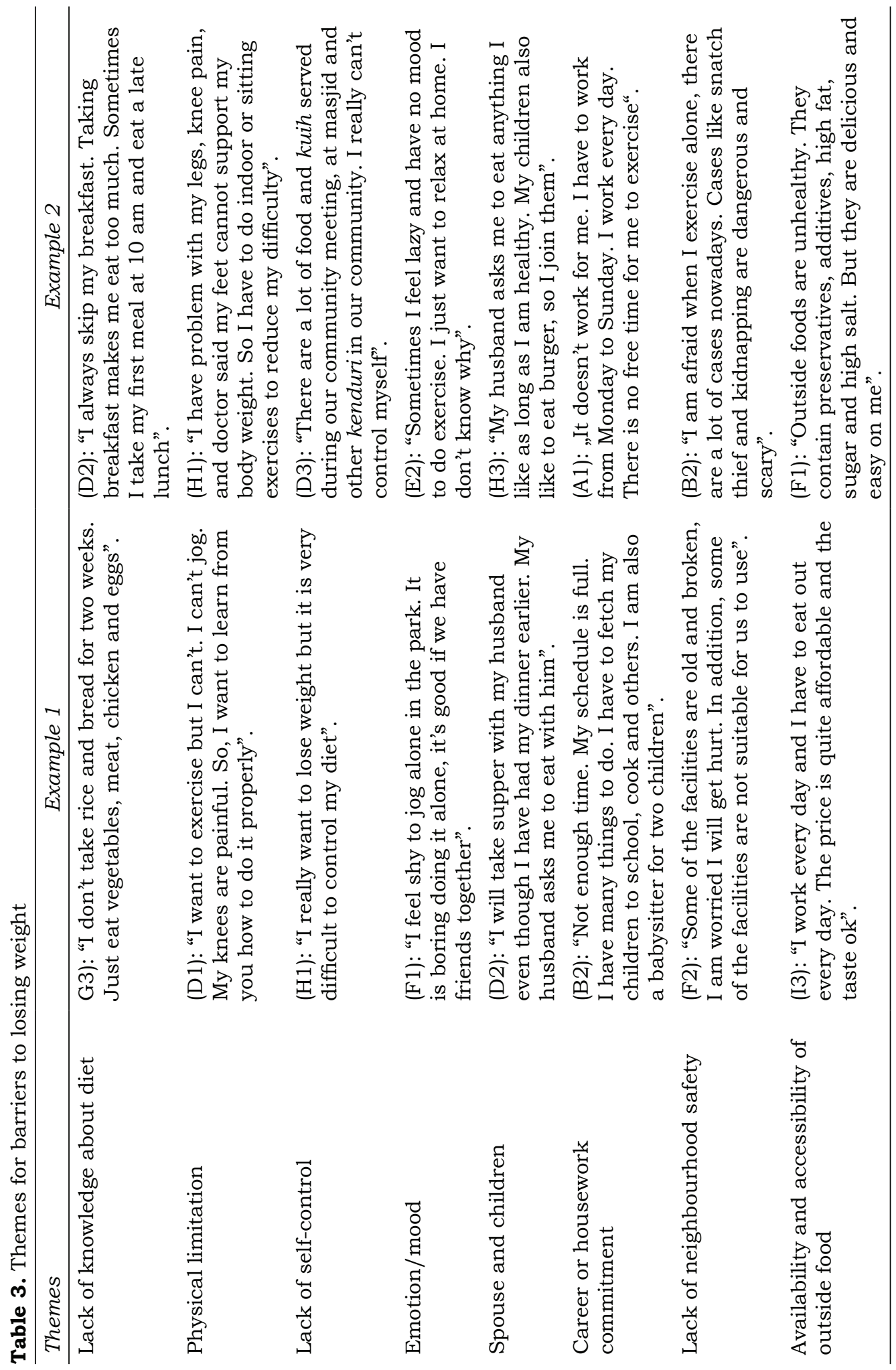


Interpersonal level involves the social relationships surrounding an individual (friends, family, spouse and children). Only one motivating factor was determined at the interpersonal level - social support from family and friends. However, family members, especially spouses and children, were also categorised as a barrier at this level, in addition to career or housework commitment.

Availability and accessibility of physical activity facilities and health information were motivating factors, and lack of neighbourhood safety was a barrier at the community level. The availability and accessibility of outside foods can be addressed as a barrier, both at the community and policy levels. Finally, healthy lifestyle programmes conducted by health clinics was identified as a motivator to weight reduction practices at the policy level.

\section{DISCUSSION}

\section{Motivating factors to lose weight}

Most of the participants had good self-awareness in developing healthy lifestyles as they showed concern about their health. This result is similar to Lofrano-Prado (2013), who reported that self-awareness was the strongest predictor to losing weight, especially among women. It has also been reported that motivation for weight loss in obese adults can be divided into three broad categories: health $(50.0 \%)$, appearance $(35.0 \%)$, and mood (15.0\%) (LofranoPrado et al., 2013). Many have the selfconfidence to reduce their weight with the assistance of the right diet and proper exercises. Women often want to look slim and have a good appearance. Therefore, having high self-motivation and the desire to have good physical appearance play an important role in influencing women to reduce their weight (Fleary \& Ettienne, 2014). A study conducted in the United States showed that women who were overweight and obese wanted to lose weight to look better (Christaldi \& Dejoy, 2012), as well as to have the physique to wear attractive, stylish and fashionable clothing (Fleary \& Ettienne, 2014). With that, extension programmes to increase awareness, knowledge, skills, motivation, and confidence would be best suited for overcoming these barriers for being physically active (Fitzgerald \& Spaccarotella, 2009).

This study also showed the importance of social support in motivating the participants to lose weight. A majority of the participants, especially women, reported that they needed support from friends and family as an encouragement. Social support from family, friends and co-workers had been identified as a key factor in successful weight loss and maintenance, as well as to practise healthy lifestyle, especially among women (Metzgar et al., 2015). Spouses are also one of the motivators for weight loss as some of participants had the support and motivation from their husbands. Relationship between two individuals, particularly husband and wife, can be an effective method to begin and sustain weight loss (Carson et al., 2013).

In addition, weight loss intervention programme should involve a group approach as social support. Peer support group and the involvement of influential people in the community are needed to provide social, physical and motivational support in effective and comprehensive obesity interventions. Group-based physical activity that encourages social interaction has become a major impetus for adults to engage in physical activities (Fitzgerald \& Spaccarotella, 2009; Bethancourt et al., 2014). Community partnership, for example, community gardening programme has been shown to improve vegetable intake, as well as reduce the BMI and waist circumference 
among obese adults in a semi-urban community (Wirdah et al., 2018).

The availability of and accessibility to physical activity facilities and health information were motivators for the participants to lose weight and practise healthy lifestyles. In addition, the participants also stated that the availability of free exercise facilities at their workplace or housing area would provide them with opportunities to practise a healthy lifestyle. The availability of sports facilities, recreational parks, and pedestrian walkways in the neighbourhood has been shown to increase physical activity and improve weight status among individuals who are overweight and obese (Siti Sabariah et al., 2014). On the other hand, according to Bethancourt (2014), lack of information can be an obstacle for individuals to participate in any physical activities.

Healthy lifestyle programmes that have been promoted in health clinics influenced our subjects to get involved in practising healthy lifestyles and becoming more active. The subjects joined healthy lifestyle programmes, namely the 10,000 steps intervention, that was conducted at the nearest health clinic. Study has shown that the 10,000 steps intervention increased physical activity, improved health outcomes, and resulted in modest reduction of body weight among overweight adults (Mokhtar et al., 2019). Therefore, it is important to increase the awareness among our community towards the importance of healthy lifestyle for overall wellbeing (Ridzuan et al., 2018). The government and stakeholders at the policy level must recognise the opportunities and actions needed to develop environments that promote healthy lifestyles as the community and neighbourhood environments are important motivators for individual behavioural change (Stulberg, 2014)

\section{Barriers to losing weight}

The main barrier to losing weight was the lack of knowledge about diet. Although most of the participants were concerned about chronic diseases and had the confidence to lose weight, unfortunately many of them misunderstood the meaning of a healthy diet. The participants believed that skipping meals, such as breakfast or dinner, was an effective practice for losing weight. The lack of nutritional knowledge among participants was a barrier to losing weight and the practice of healthy lifestyles, and as such, learning about proper dieting practices are important for weight loss (Kruegle, 2012).

Most of the participants complained they had physical limitations such as knee and leg pains, which limited their involvement in daily physical activities or exercises. Body weight affects quality of life. Increased BMI decreases scores in all quality of life domains, with the most significant negative impact in the physical domain (Kolotkin \& Andersen, 2017). This indicates that overweight individuals require help and guidance from professionals to do suitable exercises (Bethancourt et al., 2014).

Intervention programme must promote a physically active lifestyle by encouraging participants to be more active throughout the day. Participants can be encouraged to park at the far end of the parking lot and walk to the office, or to take the stairs instead of the elevator. A study has shown that an active lifestyle is just as effective as prescribed exercises for improving physical activity, cardiorespiratory fitness, blood pressure, and body composition. In fact, a physically active lifestyle may be an even better option for obese persons who have poor fitness levels and struggle with engaging in exercise for longer periods of time (Kruegle, 2012).

Participants also complained that they could not control their cravings 
for food. The participants took part in community activities such as feasts, meetings, discussions, and religious activities that serve a variety of foods. In particular, women with extended social contacts which required their participation in these community activities have access to high calorie foods served (Sharifi \& Ebrahimi, 2013). This issue needs to be considered in the development of our educational materials for weight loss interventions.

Surprisingly, women participants identified their spouses and children as barriers to lose weight. They influenced women to eat unhealthy foods and have late dinners, which contributed to weight gain. Hammarstrom (2014) reported that partners could be a major barrier to weight loss by encouraging the eating of unhealthy foods. This barrier includes difficulty in combining dietary changes with being together with their family, friends and workmates. Friends and family members tended to tempt women with high-energy and savoury foods and did not support them regarding their healthy food choices when eating at social and family gatherings (Metzgar et al., 2015).

Furthermore, career and housework commitments were reasons why participants did not exercise due to a lack of time and feeling of fatigue. One participant reported that her job as a chef and taking care of her family restricted her from doing any exercises. Similarly, one-third of low-income women in the United States claimed that time and cost were barriers for them to participate in weight loss programmes (Ciao et al., 2012) and for women to do physical activities in Iran (Sharifi \& Ebrahimi, 2013).

Most of the participants ate out several times a month to celebrate family occasions, and due to the availability and accessibility of foods outside, it was difficult to control their diets. Outside foods are cheaper, more delicious, had more variety and are available at all hours. This was one of the barriers for them to control their weight as most outside foods are unhealthy, high in calories, fat and salt. Socio-economic development in Asia, which had occurred in the past three decades, has resulted in increased food availability and changes in the diets of Asian populations. Many foods served are now refined, sweetened and fatrich, especially in the low- and middleincome communities (Ramachandran et al., 2012). Neighbourhood or community has now become a barrier for healthy eating as there are limited healthy foods available (Fitzgerald \& Spaccarotella, 2009). Therefore, focusing on teaching people how to prepare quick and healthy meals and selecting healthier food options when eating out is important (Fitzgerald \& Spaccarotella, 2009). Besides that, policies that can influence food pricing, food-related advertisement and regulations, are also important to influence people's food intake patterns and food choices.

Safety issues were also raised during discussions about physical activity. Most physical activity facilities are old and more suitable for younger rather than older persons. Clean, accessible and safe leisure facilities and parking areas are important factors in helping individuals become more active (Bethancourt et al., 2014). Some of participants claimed that incidents involving snatch thieves and traffic accidents made them unwilling to exercise in public places. A study conducted in the United States showed that subjects would perform physical activity if the environment was safe for them (Abdel-Kader et al., 2009). Therefore, the authorities should monitor safety and improve the facilities provided in the community in order to encourage people to be active. 
The themes captured in this study can be referenced when developing future interventions and strategies in weight lost intervention programmes. The SEM of health behaviour, which emphasises on environmental, behavioural, social, and psychological factors provides a comprehensive framework for understanding multiple determinants of health behaviours. SEM can be used to develop a systematic intervention by targeting the changes in mechanism at the interpersonal, intrapersonal, community, and policy levels (Fitzgerald \& Spaccarotella, 2009).

\section{Limitations and strengths}

This study has several limitations. One was the homogeneity of the sample, whereby the participants were middleaged Malays who wanted to lose weight. This may have limited and caused bias in the answers provided. Overweight adults who were not interested in losing weight should be included in future studies to fully understand the barriers and motivators to weight loss. This will provide new insights for more effective weight management strategies for the population.

A strength of the study was that the FGDs were well-organised and discussions were lively. The discussions were led interactively by a trained moderator who was able to put the participants at ease. All the participants shared their knowledge, ideas and experiences. They were more relaxed as they knew each other and had the same socio-demographic background. A focus group is ideal when used with a comparatively homogeneous group, like ours, where the participants could contribute equally to the discussion. Future studies in this area should explore barriers and motivating factors for those not interested in losing weight and to examine the relationship between socioeconomic status with the barriers and motivating factors to lose weight.

\section{CONCLUSION}

In conclusion, there were eight factors that had been identified as motivators and barriers towards weight reduction practices among adults with overweight and obesity. Information regarding healthy diets should be disseminated extensively as lack of knowledge was a barrier to losing weight. The information should also help individuals overcome their attraction to unhealthy outside foods. Findings from this study suggest that researchers should focus on an effective way to increase physical activity and exercise as physical limitation to perform exercise was one of the barriers identified. The exercises prescribed should particularly be wellsuited for people with obesity and are comfortable to encourage and increase the probability of long-term success. Families need to be encouraged to support the efforts by a family member to lose weight and to maintain weight loss on a long-term basis. From the SEM perspective, an intra- and interpersonalfocused intervention should be developed together with community level intervention in order to create an effective weight loss programme, especially targeted at individuals living in sub-urban communities.

\section{Acknowledgement}

This study was part of the "Fit, Eat, Active and Training (F.E.A.T) Project funded by Arus Perdana Grant (Code: AP 2014-025). Special thanks to external peer reviewers and all participants for their full cooperation. The efforts and dedications of the researchers, data collection team and all those involved in this project are also acknowledged.

\section{Authors' contributions}

RAT, principal investigator, conceptualised the paper and designed the study and reviewed the manuscript; PBK, assisted in drafting of the manuscript and reviewed the manuscript; WM \& 
$\mathrm{SE}$, conducted the data collection, data analysis, interpretation and prepared the first draft of the manuscript. All authors read and approved the final manuscript.

\section{Conflict of interest}

None to declare.

\section{References}

Abdel-Kader K, Unruh ML \& Weisbor SD (2009). Symptom burden, depression, and quality of life in chronic and end-stage kidney disease. Clin J Am Soc Nephrol 4(6):1057-1064.

Bethancourt HJ, Rosenberg DE, Beatty $\mathrm{T} \&$ Arterburn DE (2014). Barriers to and facilitators of physical activity program use among older adults. Clin Med Res 12(1-2):10-20.

Carson TL, Eddings KE, Krukowski RA, Love SJ, Harvey-Berino JR \& West DS (2013). Examining social influence on participation and outcomes among a network of behavioral weight-loss intervention enrollees. J Obes 2013(480630): 18. http://dx.doi.org/10.1155/2013/480630.

Christaldi J \& Dejoy D (2012). An exploration of the motivational influences of successful weight loss and maintenance. J Acad Nutr Diet 112 (9): A37.

Ciao A, Latner J \& Durso L (2012). Treatment seeking and barriers to weight loss treatments of different intensity levels among obese and overweight individuals. Eat Weight DisordStudies on Anorexia, Bulimia and Obesity 17(1): e9-e16.

Fitzgerald N \& Spaccarotella K (2009). Barriers to a healthy lifestyle: from individuals to public policy. an ecological perspective. Journal of Extension 47(1):1-8.

Fleary SA \& Ettienne R (2014). Inherited or behavior? What causal beliefs about obesity are associated with weight perceptions and decisions to lose weight in a US sample? International Scholarly Research Notices 2014(632940):1-10.

Ghee LK (2016). A review of adult obesity research in Malaysia. Med J Malaysia71(June): 1-19.

Hammarstrom A, Wiklund AF, Lindahl B, Larsson C \& Ahlgren C (2014). Experiences of barriers and facilitators to weight-loss in a diet intervention - A qualitative study of women in Northern Sweden. BMC Women's Health 14(1): 59.

IPH (2015). National Health and Morbidity Survey $V$ (NHMS V). Ministry of Health Malaysia, Putrajaya.
IPH (2020). National Health and Morbidity Survey (NHMS) 2019: Vol. I: NCDs - Non-Communicable Diseases: Risk Factors and other Health Problems. Setia Alam: Institute for Public Health, National Institutes of Health, Ministry of Health Malaysia.

Kolotkin RL \& Andersen JR (2017). A systematic review of reviews: exploring the relationship between obesity, weight loss and health-related quality of life. Clin Obes 7(5):273-289.

Kruegle E (2012). Factors that motivate obese and overweight patients to adhere to lifestyle change. Degree Thesis for Nursing (Bachelor of Nursing). Novia University of Applied Sciences, Vaasa, Finland.

Kuan PX, Ho HL, Shuhaili MS, Siti AA \& Gudum HR (2011). Gender differences in body mass index, body weight perception and weight loss strategies among undergraduates in Universiti Malaysia Sarawak. Mal J Nutr 17(1):67-75.

Lau XC, Chong KH, Poh BK \& Ismail MN (2013). Physical activity, fitness and the energy cost of activities: implications for obesity in children and adolescents in the tropics. Adv Food Nutr Res 70:49-101.

Lenio, J.A. (2006). Analysis of the Transtheoretical Model of behavior change. Appl Psychol 73-86.

Lofrano-prado MC, Hill JO, José H, Ms GS, Rodrigues C, Freitas MD \& Maria C (2013). Reasons and barriers to lose weight: obese adolescents ' point of view. $\mathrm{Br} J$ Med Med Res 3(3):1-9.

Metzgar CJ, Preston AG, Miller DL \& NickolsRichardson SM (2015). Facilitators and barriers to weight loss and weight loss maintenance: A qualitative exploration. J Hum Nutr Diet 28: 593-603.

Mokhtar R, Halim HA, Zailani MH, Isa A, Fauzi NFM (2019). Penurunan berat badan dan peningkatan kesihatan metabolik melalui program berjalan berasaskan pedometer selama 10 minggu. Jurnal Sains Kesihatan Malaysia 17(1): 21-29.

Noor Safiza MN, Rashidah A, Mohd Azahadi O, Suzana S \& Nur Shahida AA (2016). Methodology of the My Body is Fit and Fabulous at Home (MyBFF@home): An intervention study to combat obesity among housewives in Malaysia. Journal of Women's Health, Issues and Care 5:5. 
Nur Shahida AA, Nor Azian MZ, Noor Safiza MN, Rashidah A \& Cheong SM (2016). Perspective on obesity problems and associated factors to reduce weight among overweight and obese housewives: A qualitative study. Journal of Women's Health, Issues and Care 5(6).

Ramachandran A, Chamukuttan S, Shetty SA, Arun N \& Susairaj P (2012). Obesity in Asia is it different from rest of the world. Diabetes/ Metabolism Research and Reviews 28(28): 4751.

Ridzuan AR, Karim RA, Marmaya NH, Razak NA, Khalid NKN, Yusof KNM (2018). Public awareness towards healthy lifestyle. International Journal of Academic Research in Business and Social Sciences 8(10): 927-936.

Roszanadia R, Suzana S, Lee XW \& Zahara AM (2016). Effectiveness of a structured weight management programmeme at workplace among employees of a petroleum industry in Malaysia. Jurnal Sains Kesihatan Malaysia 14(2): 49-56.

Sharifi N, Mahdavi R \& Ebrahimi-Mameghani M (2013). Perceived barriers to weight loss programs for overweight or obese women. Health Promot Perspect 3(1): 11-22.
Siti Sabariah B, Siti Farrah Zaidah MY, Poh BK \& Ruzita AT (2014). The role of built environment in physical activity, diet and obesity among Malaysian children. GJPAAS 4(April): 42-47.

Stulberg B (2014). The key to changing individual health behaviors: Change the environments that give rise to them. Harvard Public Health Review. Fall 2.

Wirdah M, A'rif A \& Ruzita AT (2018). Benefits of community gardening activity in obesity intervention: Findings from F.E.A.T. Programme. Curr Res Nutr Food Sci 6(3): 700710.

Wirdah M, Poh BK, Nor Farah MF, Norhayati I \& Ruzita AT (2020). Impak Program Fit, Eat, Active, Training (F.E.A.T) terhadap status pemakanan dan aktiviti fizikal dalam kalangan dewasa berlebihan berat badan. Jurnal Sains Kesihatan Malaysia 18 (1): 71-83.

World Health Organization (2017). Obesity and overweight. Fact sheet Updated October 2017. From http://www.who.int/mediacentre/ factsheets/fs311/en/ [Retrived September 25 2017]. 